\title{
Teacher as a Decisive Factor to Enhance the Quality in School
}

\author{
Lina Vaso, PhD Candidate
}

vasolina89@yahoo.com

\section{Doi:10.5901/ajis.2015.v4n3s1p83}

\section{Introduction}

The role of teachers in teaching-educational work is considered as the most important subjective factor to the school for the realization of the learning process and success at school, therefore the time has repeatedly raised as an issue to be solved: increase the role of teachers in the educational process and further promoting his moral image.

In order to reach the top, the teacher is placed at the center of the reform process without distraction from the concrete activity that he performs in the classroom and his concrete effects on the results of the students. He serves on the institution of preparation of the future students, cadres and specialists for multi-year terms. This implies the strengthening and deepening of the scientific content of the education process, gathering experience and actuality. To accomplish his mission successfully, the teacher is required to be competent in his professional field, creative and demonstrate pedagogical mastery.

Despite the lengthy transition difficulties, teachers have increased their efforts to crack and argue the phenomena, concepts, laws, the most essential rules which promote the creative thinking of students to elaborate formative knowledge needed in their lives. Teacher's professional dedication and motivation in work have been significant factors for the planning, organization and execution of all work with students.

With his professional ability and pedagogical and psychological preparation the teacher has enabled the successful performance of educational work; certainly not to the extent necessary and in the way he wished to be, because the transition conditions did not allow the complete implementation of his illuminative aspirations and mission.

The teacher tried to include all students in the learning process by providing learning and education alternatives in terms of training students for self-learning. Seen in this light, we might say that, the criterion of professional evaluation of teachers, his level and ideological and scientific formation, is still the promotion of students' creative thinking, education of independent work habits for quick orientation and integration into life and the labor market.

The implementation of the reform to teachers was a necessity to increase their professionalism and in this respect a number of criteria were set by MES and the government regarding teachers' employment. A simple application would be inadequate for employment; other requirements such as Master degrees, knowledge of a foreign language and prequalification would also be asked in this regard. Currently, MAS also requires the teacher's portfolio, his continuous testing and qualification.

\section{Improvement of Effective Teaching Skills}

The following is an explanation of 6 essential skills that should help any teacher better teach their students with a special need when applied in the classroom setting:

\subsection{Objective}

An objective has been defined as "a clear and unambiguous description of your educational intentions for your students

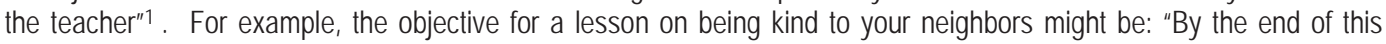
lesson, every student will state at least one thing they will do in the coming week to show kindness to their neighbors."

The teacher knowing the subject matter she will teach forms an objective by asking, "What do I want my students

${ }^{1}$ Woolfolk, 1993, p. 437 
to know after this lesson is complete?"

The clear course where the students are going is made possible through a clearly stated objective within each lesson.

Hunter (1994) includes stating of the objective as a second step of a lesson. A teacher should be keenly aware of the lessons direction and effectively communicate the objective to the students so they know what is expected of them. Stating an "instructional objective will probably help focus students' attention and thus increase achievement"2 Gronlund (2000) also shares the importance of stating a lesson objective, by indicating that stated objectives can enhance student achievement.

\subsection{Wait time}

Questioning is essential to every style of instruction. Whatever the setting, the role of questions will exist in a teaching environment. "In order to teach well it is widely believed that one must be able to question well"3. Therefore educators should be trained on effective methods when questioning students in their classrooms. One such method is the use of wait time.

Wait time can be defined as the time given to allow for student response after a question has been posed. Wait time is one aspect of questioning that deserves attention because experts agree that allowing students to process what has been asked before expecting a response is beneficial. in one study, "increasing teacher wait time had a number of effects including a decrease in the amount of teacher talk, an increase in the amount of student utterances fewer low cognitive level questions and more high level questions"4 .

Once a question has been asked by the teacher it has been suggested that a minimum often ten seconds be given before a teacher would expect to receive an adequate response (Rowe, 1987). Other researchers suggest only three to five seconds of wait time (Wilen \& Clegg, 1986). However these recommendations are based upon learners without disabilities. Children with disabilities may need more time to process the question and then to formulate an answer.

\subsection{Active Participation}

Teachers should "encourage students to respond in some way to each question"5. For example a teacher may pose a question and then ask the students to raise their hands to reply. When hands fly in the air she asks each student to share the answer with a neighbor student. This method allows the students to be actively involved in the learning process. Active participation has been demonstrated to increase positive parent and student attitudes toward learning (Morianty, 2001), and student achievement (Pratton, 1986).

This can be illustrated when a teacher poses a question to a group of young students and instantly several children who desire to share the right answer raise their hands. Other students' hands stay down out of fear that they do not know the answer, while others hands play at their sides due to lack of attention or desire to participate. The teacher calls on one student who states the correct answer then quickly moves on to the next part of her lesson leaving many of the children disappointed that they were not called on to share their responses.

The student who was allowed to state the right answer may feel confident but how do the other students feel? Those who raised their hands may be left thinking, "I knew it!" or "She never calls on me!" students who never raised their hands discover that as long as someone else talks they do not need to know the answers. active participation helps eliminate this problem by giving each student the responsibility and opportunity to be engaged in the lesson.

\subsection{Multiple Intelligence}

Walk through a college hallway during finals week and one will see a variety of studying techniques. These include the use of flash cards, students talking in a group, visual depictions drawn in notebooks, a student pacing the halls as she

\footnotetext{
2 Ibid

3 Brualdi, 1998, p. 3

${ }^{4}$ Tobin, 1987, p. 76

${ }^{5}$ Wilen \& Clegg, 1986, p. 153
} 
studies her notes and another lounging comfortably on his back browsing through a textbook. (Today we encounter this phenomenon unfortunately increasingly less, as we might say that we miss seeing in hallways or schoolyard student learning, except for the exam periods.) Study habits are as varied as the individuals who are studying. Likewise a single method of learning or teaching does not exist that can be applied successfully to everyone rather. Teachers need to be aware of what works best to meet the individual needs of each student especially those requiring special attention due to a disability.

Howard Gardner (1999) addresses the issue of reaching students of various learning styles in his book, Intelligence Reframed: multiple intelligences for the 21st century, and he states that intelligence is multifaceted and comprises several faculties that are not always dealt with in classroom coursework and procedures. His hypothesis is founded on the fact that students have individual strengths and learning styles that should be addressed in the classroom.

Gardner identifies ten basic intelligences or learning strengths: the first is body kinesthetic referring to knowledge gained through movement and body awareness dancers and athletes are often strong in this area of intelligence. Next verbal linguistic intelligence is demonstrated by a strong command in literacy and reading. Those who are scientifically and mathematically gifted often have strengths in the logical-mathematical intelligence. A strong command of rhythm combined with appreciation for and the ability to write and perform music is found in the musical-rhythmic intelligence. Engineers, surgeons and artists usually fall into the visual spatial intellectual category. Those who understand and relate well with others possess strengths in interpersonal-social intelligence. Intrapersonal-introspective intelligence refers to those with a keen awareness of their inner self.

Gardner recently added three new intelligences; naturalistic, spiritual, and existentialist. Though these strengths are recognized by some teachers many still focus primarily on the visual and auditory processing of their students. Such exclusion of the other intelligences forces many students to learn through a means which may be least natural to them

Problems often arise when teaching is conducted in only one form such as auditorally, because those students who learn best visually or via other means are at a disadvantage. Howard Gardner's Multiple Intelligence theory favors education that recognizes differences among individuals and discourages standardized linear presentations of material this results in a more equitable approach to "education"6. Teachers need to teach in a variety of ways and know their students strengths to achieve optimal learning.

\subsection{Positive Behavior Management}

Teachers must work on finding and praising positive behavior more than correcting negative behavior. Research has demonstrated the need for reinforcing positive behaviors time and again (Latham, 1997). The concept that one would rather be praised for things done correctly over being chastised for mistakes made is simple. A basic principle of human behavior teaches us that behavior responds better to positive than to negative consequences. Most people understand this but despite it, there is a strong tendency on the part of classroom teachers to manage the classroom environment coercively? .

The challenge for teachers is to be proactive and to applaud positive behavior. "Teachers allow over $90 \%$ of all of the appropriate things their students do go unrecognized; yet, when students misbehave teachers are 2 to 5 times more likely to pay attention to that behavior than they are to appropriate behavior"8. These findings illustrate the need to equip teachers with effective positive behavior management skills. As Latham added, "Teachers have simply got to learn to be much more positive and encouraging than negative and discouraging" (1997, p. 8). These skills will enable teachers to then praise students while ignoring inappropriate behaviors.

An example of a positive method of behavior management is the use of a marble jar. An empty is placed at the front of the classroom. When the teacher observes that the students are on task, she may add a marble to the jar, thus calling attention to their positive behavior. Once the jar is full, the students will earn a prearranged reward. Another method involves having the students earn points for appropriate behavior. Once a set amount of points is earned, a type of reinforcement is implemented. "Research has shown that the most effective way to reduce problem behavior in children is to strengthen desirable behavior through positive reinforcement rather than trying to weaken undesirable

\footnotetext{
${ }^{6}$ Armstrong, 1993, p. 47

${ }^{7}$ Latham, 1997, p. 7

$8 \mathrm{lbid}$
} 
behavior using aversive and negative processes"9. The fundamental core of the above examples is that the teacher takes a positive approach to preventing maladaptive behaviors in the classroom.

\subsection{Attention}

When students are not paying attention there is little point in continuing with the lesson. "I have observed that a key to on task behavior is to quickly engage students in the learning activity. I have found that the sooner teachers get students on task the easier it is to keep them on task"10. Effective teachers will be aware of ways to pull students into their lessons and keep them focused. One method is Madeline Hunters Direct Instruction teaching approach (Hunter, 1994). The first step in this plan is the anticipatory set or attention getter and involves activating background information of the student. "At the beginning of a lesson the teacher needs to establish a positive ... attitude of readiness in students" ${ }^{11}$.

In one of the questionnaires for assessing the image of the teacher, we obtained the following evaluation by the students:

"We appreciate those teachers who have erudition wide, who own deep knowledge and are masters of their profession, who materialize with their behavior the standards of democracy in school life, who in any case are prudent and reasonable, who try to clarify the students wisely, patiently and calmly, who are simple, sociable and polite with students, who have positive mood and organize joint activities with students, who are demanding, but principled and fair, who respect the personality of the students, who know how to find and rely on positive traits of students to design a citizen."12

\section{Classroom Management according to Educational Standards}

Classroom management, in our concept means the running and organization of the learning process. In order to realize a successful teaching process teacher need to know:

1. Theoretical treatment on classroom management

2. Effective methodology for practical application in the classroom

Teacher faces every day cases, which come suddenly, how he may avoid problems that impede the normal development of the learning process; it depends on how he possesses the management skills and knowledge of classroom. Obviously, these problems have psycho-pedagogical, objective and subjective character, and teacher should overcome those with patience and understanding during the teaching process.

"Teaching methodology"13 has determined that the management of the lesson concerns the management and organization of learning, aiming to maximize the productive involvement of students in learning. Notwithstanding that at the beginning of reforms, increase the independence of students often exceed the normal limits, the teachers were patient buffers to shade their childish outbursts. It happened and still happens today, that we have overcrowded classes of over 35-45 students. As a result of this overload, in these classes the teacher often encounters students destabilization. In the majority of cases when the teacher is correcting a student's work, or helping someone else, even while explaining, they are distracted, start conversation, whisper, bother each-other and laugh, etc. From the recommendations of the "teaching methodology" we learn that the main causes of students' indiscipline in the classroom are: frustration, mental fatigue and the lack of ability to perform the tasks.

The teacher is subjective important factor in training, with his professional competence and didactic and methodical preparation he plans, organizes and performs all work with students, and enables the creation of basic conditions for successful teaching job performance.

According to Gary D. Borich the two most important aspects, dealing with the beginning of learning, are punctuality and mental adjustment. It is very important if the teacher arrives in time to start the learning process, because punctuality in this direction would demonstrate the personal example, how necessary, fair and rational it is to respect the time and learning hours.

\footnotetext{
${ }^{9}$ Bijou, 1988, p. 444

10 Latham, 1997, p. 6

11 Slavin, 2003, p. 226

12 EO of Saranda, Analysis of the survey conducted by school psychologists, March 2012

${ }^{13}$ Gary D. Borich, Effective Teaching Methods (Teaching methodology, 3rd Edition) Translated by Musai Bardhyl, ALBGRAF, Tirana 2003, p.206
} 
Obviously, classes start according to the daily plan that the teacher disposes and in order to present the purpose of the course, the teacher asks questions to students, which connect the past unit with the present one, aspects which ensure the teacher that the students' mental mobilization has been provided.

Teacher should pay basic care to the end of the lesson, the allotted time and its reasonable use. When the class ends, or when the bell rings, students' learning stops, they have no interest on the lesson anymore and continuing the teaching process after that time would be irrational to the teacher and unfair to the students.

Classroom environment, created by the teacher, can have an impact on student motivation, which is reflected in their active attitude toward learning. Such an environment constitutes what is called "classroom climate." 14

The teacher is a crucial factor in creating a positive climate, because as Haim Ginott states: "I've come to a frightening conclusion that I am the decisive element in the classroom. It's my personal approach that creates the climate. It's my daily mood that makes the weather. As a teacher, I possess a tremendous power to make a child's life miserable or joyous. I can be a tool of torture or an instrument of inspiration. I can humiliate or heal. In all situations, it is my response that decides whether a crisis will be escalated or de-escalated and a child humanized or dehumanized."15 "The Future" Magazine) ${ }^{16}$.

Therefore, a loving atmosphere should be created in the classroom; learning should be a joyful process by building confidence in students, making them to be explorers (discoverer, researchers).

The teacher has the upper hand in class, classroom climate, communication and motivation of the students, the organization of learning activities. With this commitment, teachers with good professional and cultural level have tried to create a loving atmosphere in class, turning the learning process in a blissful one with confidence in students.

The most important aspect that has to do with the beginning of learning has been punctuality of teachers. It is very important if the teacher arrives in time to start the learning process, because punctuality in this direction would demonstrate the personal example, how necessary it is to respect the time and learning hours. But there have been cases in village schools that the class started late, especially after recess time, finishing without a repetition or summary of the topic developed.

Other causes of distraction to students in the classroom have come from lack of communication skills of teachers to students, but particularly from unplanned lessons and interesting ones by teachers. This has led to the de-motivation of students to learn, as it has damaged the development of positive relationships in the classroom.

\section{Quality of Education Problem in the Contemporary Education}

\subsection{The problem of quality of education is more important in a reform school}

At the present time the Albanian school is in the center of public attention regarding the implementation of national projects in the field of education. In the context of increasing demands for intellectual and moral training of students, future changes in relation to financial autonomy of educational institutions, long-term competition in the market of educational services, the problem of quality of education is more important in a reform school. Compliance with the students' knowledge to state standards, the successful work of the institution, the activities of each teacher - this is the meaning of quality education.

How can we define the quality in modern school? Undoubtedly, the quality consists of report of goals and outcomes that reflect the level of knowledge and skills of students, the level of organization and implementation of the educational process and the conditions under which it takes place. It is therefore necessary to define specific criteria for the operation of these conditions; first, the school itself - "open theater which orates", secondly, the material and technical basis of the school and thirdly, the educational curricula and scientific and methodical work.

Today is an obvious need for the improvement of the quality of educational process the search for the most effective forms, methods and means of teaching, the introduction of modern educational technologies. We are keen to establish a consistent interest in this subject, to find appropriate methods and techniques that would be useful largely for educational quality and which contributed to the formation of knowledge and skills of students.

14 Gary D. Borich, Effective Teaching Methods (Teaching methodology, 3rd Edition) Translated by Musai Bardhyl, ALBGRAF, Tirana 2003, p. 210

${ }^{15}$ www.google.al/search?q=haim+ginott+teacher\&espv; Haim G. Ginott, Teacher and Child: A Book for Parents and Teachers

${ }^{16}$ http://eminduraku-ks.com/files/Revista\%20Ardhmeria\%20l-2014.pdf 
To do this, we must build a lesson which should be crucial to the unity of the objectives of learning, development, education; so we need to choose carefully and fix the training material, creating optimal conditions for the solution of educational problems. If we could refer as a guide to the Letter of Abraham Lincoln addressed to his son's teacher, it is embodied the whole demand for a qualitative education and educational at the same time. Since that time the things changed, technologies have been modernized, but the essence still remains the same. "Teach him if you can the wonder of books, but also give time to ponder the extreme mistery of birds in the sky, bees in the sun and flowers on a green hill." 17

In our opinion, the primary action through independent and creative work of students in the classroom under the guidance of a teacher is one of the most effective ways to improve quality in education. Therefore, learning requires creating an atmosphere, the catalytic and cognitive action of students and improving the quality of education.

We should not forget the individualization of learning, which includes accounting skills and abilities of each child. Unfortunately, our educational system for a long time had no real mechanisms to carry out an individual approach to pupils and students. The school is not as effective in the formation of the human personality, because this requires an infinite number of other mechanisms; but it is destined to prepare the student of today and tomorrow's student to perform certain social functions, when entering the great world of work.

Modern education system drives schools to implement student-centered learning. Consequently, the development and education of the individual, who is able to influence the formation of intellectual and educational potential, shall be submitted in the first place in school education. Therefore, in order to unlock the creative potential of students, their individual ability, to generate the quality associated with the future profession, in the practice of forms of the learning school should be used methods such as tutorials, presentations, classes, conferences, games of business, workshops, defense projects, etc. The organization of research work of pupils and students takes a special place in this series. These forms of work contribute to the discovery of individuality and creativity of each student.

In an article of "Teacher" Magazine, it is designed a safe way of how all together we can realize a value in increasing the quality:

"School psychologists or social workers should work closely with students to plan their course of studies, to support their performance in school, to review progress, set academic goals and to implement academic interventions. School counselors should communicate with teachers and families to provide updates on the achievements of pupils, and to further recognize and motivate their successes. And furthermore:

School counselors should be focused on the overall development of students, to enable emotional learning, to motivate students to activities and choices based on their interests, to build home-school-community alliances and to provide the continuous individualization of attention to student success. School counselors conduct individual facilitation and group counseling, and counseling of interventions needed in crisis situations.

Career Counseling and post-secondary to help students understand their strengths and talents and how these skills can be used in different branches of the university and career. School counselors facilitate educational wide activities and provide guidance lessons regarding post-secondary planning. School psychologists facilitate students in the admissions process in general secondary education or professional education and in all the next steps for their secondary education and higher education. As part of the roadmap to school, school psychologists also facilitate guiding lessons, covering each of these areas. ${ }^{18}$

\section{Conclusions and Recommendations}

The quality of school and education in today's global society of knowledge, which relies on several main pillars such as democracy, justice, tolerance, mobility and equality, obviously bears responsibilities and challenges for all education workers. Quality in education is a complex notion, which is connected primarily with the quality of the educational product, but increasingly more the quality of the active citizen who invests the acquired knowledge for the benefit of economic and social development of the country.

Schools should be accountable for the outcomes. Therefore, the Ministry should set standards and make schools accountable for learning outcomes (e.g. for the understanding. reading comprehension, computer skills, etc.) and give schools and teachers freedom to act.

\footnotetext{
17 http://www.lajme.gen.al/2014-09-01/abraham-lincoln-i-drejtohet-me-nje-leter-mesusesit-te-djalit-te-tij-letra-qe-duhet-lexuar-cdo-nje-shtator.html

18 'Teacher' Magazine, Tirana, no.5 2015, p 19 
Curriculum reform should follow the new texts, guide teachers and learning materials, changes in teaching methods and new measures of learning outcomes.

Albania will need to perform intensive training of new and existing teachers' staff, including the introduction of new teaching methods, use of teaching materials and methodology of opinions. Such development should be mandatory.

\section{References}

Education Office Archive of Saranda, 2004, file 27

RED in Vlora, in January 2009, File 7, p. 23

D. Borich, Effective Teaching Methods (teaching methodology, $3^{\text {rd }}$ Edition) Translated by Musai Bardhyl, ALBGRAF, Tirana 2003, p. 206

Gary D. Borich, Effective Teaching Methods (teaching methodology, $3^{\text {rd }}$ Edition) Translated by Musai Bardhyl, ALBGRAF, Tirana 2003, p. 210

EO of Saranda, September 9, 2009, File 11, p.3, .7

EO of Saranda, October 23, 2009, File 13, p.11

EO of Saranda, June 12, 2007, File 17, p. 4

EO of Saranda, The analysis of the survey conducted by school psychologists, March 2012

ZA Sarandë, 9 shtatorr 2009, Dosja 11, fq.6

www.google.al/search?q=haim+ginott+teacher\&espv ; Haim G. Ginott, Teacher and Child: A Book for Parents and Teachers

http://eminduraku-ks.com/files/Revista\%20Ardhmeria\%20l-2014.pdf 